\title{
Las plaquetas del Parpalló: la obra de Valentín Villaverde Bonilla
}

\author{
E. Ripoll Perelló
}

He aquí una obra largamente esperada y deseada, la del Prof. V. Villaverde Bonilla, recientemente incorporada a nuestras bibliotecas '. Pero, seános permitido en primer lugar recordar sus antecedentes y evocar algunos recuerdos.

Hace más de cincuenta años, en 1942, apareció en Madrid el libro del Prof. Luis Pericot, La cueva del Parpalló (Gandía) ${ }^{2}$. La coyuntura del momento era absolutamente negativa en múltiples aspectos: el país se arrastraba en las tristes secuelas de una guerra fraticida y en lo internacional se vivian algunos de los días más negros de la Segunda Guerra Mundial. Con ello, cualquier logro humanístico -y aquel libro lo era-, quedaba relegado a la espera de tiempos mejores. Por este motivo hasta los años cincuenta no empezó a hablarse de la espléndida obra del Dr. Pericot en los círculos internacionales de la ciencia prehistórica. Incluso - y estamos hablando de algunos investigadores franceses - se ponían en duda algunos de sus asertos y descubrimientos. Es este un primer testimonio personal como algún otro que nos permitiremos añadir a esta nota.

El libro del Dr. Pericot, elaborado principalmente durante los tres años de la Guerra Civil, exponía los resultados de su excavación de la Cova del Parpalló en los años 1929-1931, una de las primeras empresas del Servicio de Investigación Prehistórica (SIP) de Valencia, fundado poco antes por Don Isidro Ballester Tormo. En su contenido había dos cosas

\footnotetext{
1 Valentín Villaverde Bonilla, Arte paleolítico de la Cova del Parpalló. Estudio de la colección de plaquetas y cantos grabados y pintados. Textos preliminares de Clementina Ródenas Villena y Josep Bresó Olaso. Prólogo de Bernat Marti Oliver. Diputació de València, Servei d'Investigació Prehistórica. Valencia, 1994, vol. I, 404 págs., 56 figs.; vol. II, 158 págs., 316 figs. (33 x 24$)$.

2 Luis Pericot Garcia, La cueva del Parpalló (Gandia). Consejo Superior de Investigaciones Científicas. Madrid, 1943. 351 págs., 650 figs. y XXXII láminas.
} 
notables y novedosas: la existencia de un Solutrense peculiar, con sus puntas de flecha de aletas y pedúnculo y sus puntas de muesca de retoque abrupto, y la presencia en todos los niveles de varios centenares de plaquetas grabadas o pintadas, o ambas cosas a la vez. No es esta la ocasión para ocuparnos de aquel primer aspecto, aunque recordaré, como ejemplo, que Denise de Sonneville-Bordes y François Bordes no abandonaron sus reticencias hasta que encontraron con sus propias manos algunas de aquellas piezas en nuestras excavaciones de Cueva de Ambrosio (Vélez Blanco, Almería) el año 1961. Da pie a ocuparse del segundo aspecto la innovadora obra del Dr. Villaverde que queda descrita en la primera referencia. De la labor preparatoria de la misma ya se habian ido conociendo aspectos parciales en trabajos menores del autor aparecidos en los últimos años y que, por suerte, sigue ocupándose del tema ${ }^{3}$.

La primera plaqueta del Parpalló, con grabados, fue encontrada por el Abate Henri Breuil en una de sus prospecciones durante la guerra de 1914-1918. Su proyecto de efectuar excavaciones en el yacimiento quedó sólo en eso, tal como explicó en su día el llorado Enrique Plá ${ }^{4}$. Pero Breuil, con su autorizada opinión y buen consejo, estuvo en los orígenes de la empresa del Dr. Pericot, al igual que, años después, ambos influyeron para que el que suscribe llevara a cabo la excavación de Cueva de Ambrosio. De este modo se pusieron en valor los dos yacimientos fundamentales para el conocimiento del Solutrense llamado "de facies ibérica".

En su libro, el Dr. Pericot, presentó 570 dibujos de plaquetas (66 con pintura). Estos dibujos, como los del material lítico y óseo, fueron obra o fueron pasados en limpio por el gran dibujante que fue don Francisco Benítez Mellado, que había sido colaborador del Prof. Eduardo Hernández-Pacheco y que llegó a Barcelona en los primeros meses de la Guerra Civil. Hay que añadir, además, que el Dr. Pericot siempre tuvo entre sus proyectos el de "volver" al estudio de las colecciones de materiales y de plaquetas del Parpalló. Pero otros afanes llenaron también su vida de in-

\footnotetext{
3 Algunos escritos recientes del Dr. Villaverde: Valentín ViLLAVERDE BONILLA, «Análisis del bestiario de la colección de arte mueble de la Cova del Parpalló", Veleia, 8-9, 1991-1992, págs. 65-97, con figs.; ID., "Arte solutrense de la España mediterránea", Férvedes, 1, 1994, págs. 149157; ID., "Arte mueble de la España mediterránea: breve síntesis y algunas consideraciones teóricas", Complutum, 5, 1994, págs. 139-162, 8 gráficos; ID., "Le Solutréen de faciès ibérique: caracteristiques industrielles et artistiques", en Le solutréen en Péninsule lbérique, Mâcon, Musée de Solutré, 1994, págs. 10-29, con figs.; ID. (con R. MARTinez VALLE), “Características culturales y económicas del final del Paleolítico superior en el Mediterráneo español», en Los últimos cazadores, Alicante, Instituto de cultura "Juan Gil-Albert", 1995, págs. 79-117, con figuras.

4 Enrique Plá Ballester, "El Abate Breuil y Valencia”, (E. Ripoll Perello, ed.), Miscelánea en homenaje al Abate Henri Breuil (1877-1961), t. II, Barcelona, IPA, 1965, págs. 280-286.
} 
vestigador y, en sus últimos años, sólo llegó a publicar algunas breves notas sobre la cueva de Gandia. En el verano de 1957, junto con el eficaz Don Vicente Pascual y algunos colaboradores, acompañamos al Dr. Pericot a la cueva para excavar el muy desmoronado testigo que él había dejado y lo poco que quedaba del yacimiento en el pasillo de la entrada. El Dr. Pericot tenía la esperanza de encontrar plaquetas. En lo que cabía, todo fue excavado por niveles y cribado, pero los resultados fueron muy pobres y nulos en lo referente al arte. Convendría exhumar la libreta de notas del Dr. Pericot referente a esta que fue su última campaña en el Parpalló. Allí mismo nos decía que esperaba mucho de nuevos descubrimientos - ya hablábamos de Cueva de Ambrosio- conocidos o por descubrir y que era necesario volver sobre los materiales y las casi 600 plaquetas de su propia excavación, lo que correspondía a una nueva generación de prehistoriadores. $Y$ así ha sido. Ahora, en su obra, el Dr. Villaverde ha contabilizado más de 6.000 caras, que se estudian tras una minuciosa labor de gabinete en su calco, dibujo, fotografía y descripción. Todo ello es el resultado de un arduo trabajo que ha durado más de diez años, contando con un eficiente grupo de colaboradores.

Imposible resumir aquí el complejo y denso contenido de una obra de tal amplitud. Por ello nos limitaremos a señalar los hitos fundamentales que en ella se encadenan. En el cap. I, «bases culturales y cronoestratigráficas de la secuencia artística del Parpalló", se señalan las características generales del Paleolítico Superior de la fachada mediterránea de la Península, en particular la definición de su Solutrense (y aquí podemos ver con agrado como el autor vuelve con frecuencia a conceptos que ya expresó el Dr. Pericot), la del Magdaleniense, en particular el inferior (para el que el autor habla de un "aire badeguliense", y es bueno recordar que el Dr. A. Cheynier hizo una detallada visita al Parpalló y examinó sus materiales), y las dataciones radiocarbónicas.

El cap. 2 se refiere a la "metodologia" y sirve de introducción a los que siguen. En el cap. 3 se estudian las «dimensiones y agrupación por sectores", todo ello reflejado en cuadros muy detallados e ilustrativos. La fundamental parte temática (especies, asociaciones y posibles escenas) y técnico-estilistica (técnicas de ejecución, perspectiva, encuadre, formas, articulaciones, etc.) se inicia en el cap. 4 con «los zoomorfos", con 142 densas páginas ilustradas con figuras o fotografías de detalle y cuadros evolutivos. El análisis del bestiario se efectua sobre 766 individuos identificados (aunque los «indeterminados", representan un $42 \%$ del total). Con algunas excepciones, los animales representados son: cápridos, équidos, cérvidos y bóvidos, en orden decreciente en cuanto a su número. Los valores correspondientes se comparan con cuatro conjuntos parietales 
cantábricos y los muebles del Abri Murat y de La Madeleine. $Y$ hace muy bien el autor en dedicar unas páginas esclarecedoras al tema hoy recurrente de la "relación entre la fauna representada y la fauna consumida". Esta problemática recibe un nuevo enfoque en un texto muy apretado titulado «la aplicación del análisis factorial a los resultados del estudio técnico y estilístico de los zoomorfos y algunas consideraciones de orden secuencial". Son estas del cap. 4 unas páginas sobre las que los tratadistas de arte prehistórico deberán volver con frecuencia.

El cap. 5 está dedicado a "los antropomorfos" (algunos dudosos) y el 6 a «los signos». La riqueza de estos últimos en el Parpalló da lugar a otro modélico estudio monográfico de 111 páginas, con ilustración y cuadros muy detallados. Renunciando a las tipologías de P. Casado y de A. Leroi-Gourhan por inaplicables al Parpalió, Villaverde establece la suya propia que consideramos exhaustiva en lo que se refiere al arte parpallonense y que podrá aplicarse a otros lugares. Comprende los siguientes apartados: banda de lineas paralelas, banda de trazos cortos paralelos, dentado, escaleriforme, zig-zag, ángulo, aspas, arboriforme, huso, laciforme, ramiforme, línea quebrada, haz de líneas, haz de líneas formando bandas, haz de trazos cortos, haz de trazos cortos formando bandas, trazos pareados, trazos pareados formando banda, puntuaciones, banda quebrada de rayado múltiple, reticulado, rectángulo, círculo, espiral, claviforme, superficie raspada, banda raspada, líneas sueltas, superficie pintada y diversos, o sea un total de 31 tipos. De esta enorme y compleja variedad se estudia y analiza la "evolución por períodos" (tanto desde el punto de vista cronológico como del evolutivo interno) debidamente razonado y con el apoyo de abundantes estadísticas. Luego se pasa a la "aplicación del análisis factorial a los resultados del estudio de los signos", lo que permite pasar a las "asociaciones", en particular las relacionadas con los propios signos y con los zoomorfos.

Obtenidos aquellos resultados, el cap. 7, «la secuencia artística de Parpalló en el contexto de la España mediterránea", es recapitulativo y recurre también con frecuencia al referente del espacio franco-cantábrico. Son 60 páginas cuyo contenido es de lectura obligada para cuantos se ocupan de arte prehistórico en nuestro pais y fuera de él (los especialistas franceses e ingleses deberían leer con atención este texto fundamental). Con muy ajustadas comparaciones, la secuencia iconográfica del Parpalló se establece de forma pormenorizada hasta culminar en la especificidad regional del estilo IV cuyo paradigma es EI Parpalló y que queda definido como arte solutrense evolucionado.

El vol. Il contiene el inventario total de las plaquetas y cantos estudiados al que sigue el repertorio gráfico. No podríamos cerrar esta breve nota 
sin hacer referencia a la bella ilustración de la obra. Las magníficas láminas en color y los abundantes dibujos a la línea constituyen un muy extenso repertorio iconográfico al que será obligado recurrir durante mucho tiempo. Dicho corpus es tan rico que, sumándole los descubrimientos de los años recientes, ya no se puede decir que el arte paleolítico peninsular extra -cantábrico sea la "periferia".

La tradición de los grandes libros - de contenido y de tamaño- sobre arte prehistórico, está felizmente continuada por los volúmenes de $\mathrm{V}$. Villaverde Bonilla que ha editado el SIP valenciano. Por los largos años en que el que esto escribe trabajó al lado del Dr. Pericot, piensa que puede asegurar que él se habría sentido satisfecho por este notable trabajo. También se sentiría orgulloso Don Isidro Ballester, el "padre" del SIP, que siempre aseguraba que El Parpalló era lo más importante que había hecho su organismo en el ámbito de la Prehistoria. Desde estas líneas felicitamos al autor y al gran centro de investigación que es el SIP. Lo hacemos en la convicción de que esos dos volúmenes marcan un hito que honra a la investigación española. 


\section{E. RIPOLL PERELLÓ}
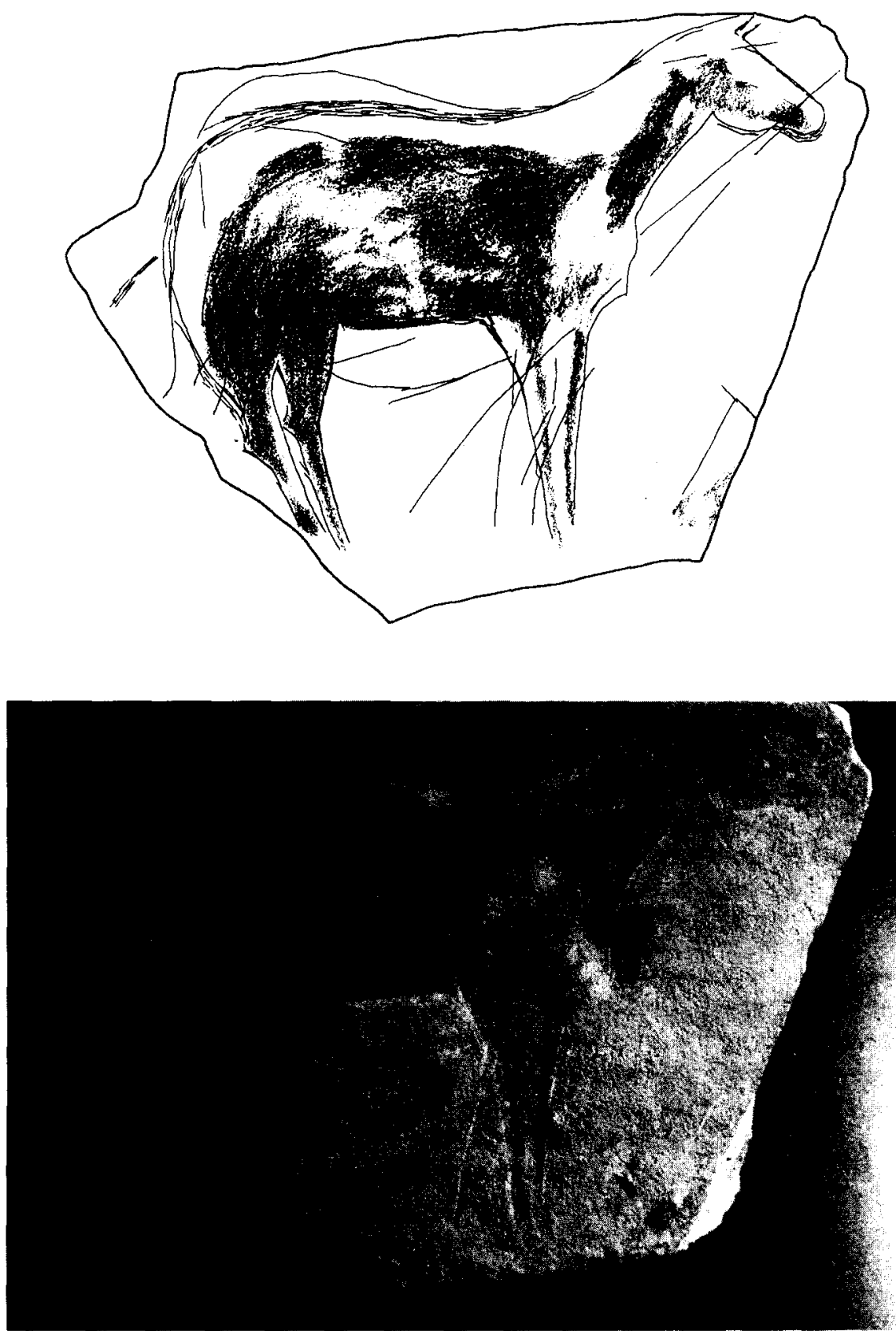

Figura 1. Plaqueta del Parpalló. 